\title{
Electrolytic resistance of solution layers at hydrogen and oxygen evolving electrodes in alkaline solution
}

Citation for published version (APA):

Janssen, L. J. J., \& Barendrecht, E. (1983). Electrolytic resistance of solution layers at hydrogen and oxygen evolving electrodes in alkaline solution. Electrochimica Acta, 28(3), 341-346. https://doi.org/10.1016/00134686(83)85132-9

DOI:

10.1016/0013-4686(83)85132-9

Document status and date:

Published: 01/01/1983

Document Version:

Publisher's PDF, also known as Version of Record (includes final page, issue and volume numbers)

Please check the document version of this publication:

- A submitted manuscript is the version of the article upon submission and before peer-review. There can be important differences between the submitted version and the official published version of record. People interested in the research are advised to contact the author for the final version of the publication, or visit the $\mathrm{DOI}$ to the publisher's website.

- The final author version and the galley proof are versions of the publication after peer review.

- The final published version features the final layout of the paper including the volume, issue and page numbers.

Link to publication

\section{General rights}

Copyright and moral rights for the publications made accessible in the public portal are retained by the authors and/or other copyright owners and it is a condition of accessing publications that users recognise and abide by the legal requirements associated with these rights.

- Users may download and print one copy of any publication from the public portal for the purpose of private study or research.

- You may not further distribute the material or use it for any profit-making activity or commercial gain

- You may freely distribute the URL identifying the publication in the public portal.

If the publication is distributed under the terms of Article 25fa of the Dutch Copyright Act, indicated by the "Taverne" license above, please follow below link for the End User Agreement:

www.tue.nl/taverne

Take down policy

If you believe that this document breaches copyright please contact us at:

openaccess@tue.nl

providing details and we will investigate your claim. 


\title{
ELECTROLYTIC RESISTANCE OF SOLUTION LAYERS AT HYDROGEN AND OXYGEN EVOLVING ELECTRODES IN ALKALINE SOLUTION
}

\author{
L. J. J. JANSSEN and E. BARENDRECHT
}

\begin{abstract}
Department of Chemical Technology, Laboratory for Electrochemistry, Eindhoven University of Technology, P.O. Box 513, 5600 MB Eindhoven, The Netherlands
\end{abstract}

(Received 6 April 1982; in revised form 16 August 1982)

\begin{abstract}
During alkaline water elcctrolysis, additional cnergy losses occur owing to the presence of bubbles in the solution, particularly close to both the gas-evolving electrodes.

For both hydrogen and ox ygen-evolving disc electrodes (diameters from 0.2 to $2.0 \mathrm{~mm}$ ) in $\mathrm{KOH}$ solutions, the reduced increase in ohmic resistance, $\Delta R^{*}$, has been determined by the alternating current-impedance method.

It has been found that, for hydrogen-evolving electrodes, $\log \Delta R^{*}=\mathrm{a}_{1}+\mathrm{b} \log i$, where the exponent $\mathrm{b}$ at $0.1 \mathrm{~A} \mathrm{~cm}^{-2}<i<5 \mathrm{~A} \mathrm{~cm}^{-2}$ does not depend on the diameter, position and material of the electrode, pressure and temperature but does significantly depend on $\mathrm{KOH}$ concentration. The factor $\mathrm{a}_{1}$, bowever, being dependent on the position, height and material of electrode, temperature and $K O H$ concentration. $\Delta R^{*}$ cannot be expressed for the oxygen-evolving electrode by a general equation, due to the coalescence behaviour of oxygen bubbles.

Moreover, it has been established that the Bruggemann equation is useful to determine the ohmic resistance of a solution layer contairing gas bubbles of different size at which each bubble adheres to the electrode surface.
\end{abstract}

\section{NOMENCLATURE}

a empirical constant

b slope of $\log \Delta R^{*} / \log i$ curve

$d_{\mathrm{e}}$ diameter of working electrode

$D_{b} \quad$ diameter of adhered bubble

i current density

$m$ number of a bubble

$m_{e}$ total number of bubbles on an electrode

$n \quad$ bubble density on electrode surface

pressure

$R$ ohmic resistance of a solution layer at the working electrode

$\boldsymbol{R}_{0} \quad \boldsymbol{R}$ at $i=0$

$\Delta R^{*}\left(R-R_{0}\right) / R_{0}$

$T$ temperature

$x$ distance from the electrode surface

$Z$ impedance of electrolytic cell

$Z^{\prime} \quad$ real component of $Z$

$Z^{\prime \prime}$ imaginary component of $Z$

$\varepsilon \quad$ gas void fraction

p specific resistance of bubble-containing solution

$\rho_{0}$ specific resistance of bubble-free solution

$\omega$ frequency of alternating current

\section{INTRODUCTION}

During alkaline water electrolysis energy losses take place owing to presence of gas bubbles in the solution of the electrolytic cell. In particular, the solution layers with a thickness less than about $1 \mathrm{~mm}$ at both gasevolving electrodes contribute to the total ohmic resistance of the electrolytic cell[1].

To investigate bubble effect on the ohmic resistance of a thin solution layer at a gas-evolving electrode, the resistance of this layer was determined by the alternating current impedance method.
For both hydrogen and oxygen-evolving disc electrodes the ohmic resistance was determined as a function of current density varying a number of parameters, such as position, diameter and material of the electrode, temperature, pressure and $\mathrm{KOH}$ concentration.

Part of the experimental results given in the present paper is based on experimental results published by de Jonge et al.[2]. They calculated an average gas void fraction for a solution layer with a thickness of $0.39 d_{e}$ at the gas-evolving disc electrode with diameter $d_{\mathrm{e}}$. However, the gas void fraction within this layer was a function of the distance to the surface of the gasevolving electrode. Consequently, the given data of gas void fraction are of modcrate intercst. In the present paper a unified relation is proposed to describe the bubble effect on the resistance increase.

\section{EXPERIMENTAL}

A roughly 700 or $400 \mathrm{~cm}^{3}$ glass vessel served as the electrolytic cell; the cell was thermostatted. A $12 \mathrm{~cm}^{2}$ platinum counter electrode was placed $5 \mathrm{~cm}$ away from the small working electrode $(0.5-4 \mathrm{~mm}$ in diameter). The working electrode was melted in a glass tube having an outer diameter of $7 \mathrm{~mm}$. The nickel and gold working electrodes were prepared by electrodeposition of a $12 \mu \mathrm{m}$-thick metal layer on a disc-shaped cross-section of a platinum wire. The platinum working electrode was made from a platinum wire and the glassy carbon electrode from a bar. Two types of electrodes, viz horizontal and vertical electrodes, were used.

The electrical scheme of the set-up consisting of an 


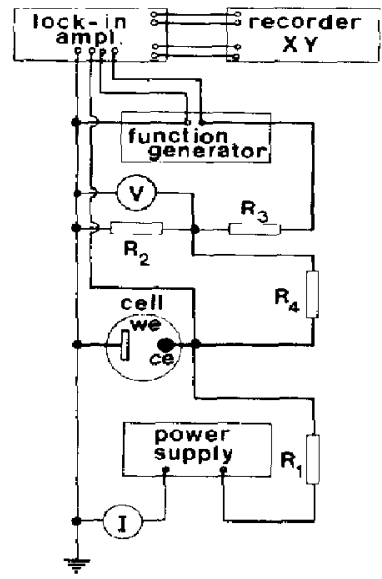

Fig. 1. Electrical scheme of electrolytic and measuring circuit.

electrolytic and a measuring circuit is given in Fig. 1 . The constant electrolytic current was supplied by a power supply (Philips PE 4832, 0-500 V) and measured with a $d c$ micrometer (Philips PM 2436).

An alternating voltage of $1 \mathrm{~V}$ was supplied by a function generator (Hewlett-Packard 3310 A) to a Lock-in Amplifier (Princeton Applied Research, model 129A). With the aid of two resistors $\left(R_{2}=4\right.$ and $R_{3}=36 \mathrm{k} \Omega$ ) an alternating voltage of $0.1 \mathrm{~V}$ was placed across the electrolytic cell.

A carbon resistor of $10 \mathrm{k} \Omega, R_{4}$, with a pure ohmic characteristic, was placed in the measuring circuit reaching a constant small alternating current through the electrolytic cell.

It is noted that the sensitivity of the $Z^{\prime}$ and $Z^{\prime \prime}$ signals strongly affects the results obtained. The choice of these sensitivities was determined with an impedance network consisting of two resistors and a capacitor parallel to one of the resistors.

To minimize current change in the electrolytic circuit during the series of experiments a resistor of $2 \mathrm{k} \Omega, R_{1}$, was placed in the electrolytic circuit.

During the series of experiments, except those at atmospheric pressure, the electrolytic cell was placed in a 31 high-pressure glass vessel. To obtain a higher than atmospheric pressure the vessel was connected to a nitrogen cylinder with a high nitrogen pressure. Pressures lower than atmospheric pressure were adjusted with a vacuum pump.

Before starting a series of experiments the electrode was generally polarised for $1 \mathrm{~h}$ at the highest current in the series. To abtain the most reproducible results, the current was decreased in steps from high to low values during the series.

To check the ohmic resistance measured by the impedance method mentioned, the ohmic resistance for a gas-evolving electrode was also determined by the well-known current-interrupter technique in which the tip of the Luggin capillary was placed about $20 \mathrm{~mm}$ from the surface of the gas-evolving electrode.

Unless otherwise stated, the standard conditions are: $1.0 \mathrm{~mm}$ diameter of working electrode, $7 \mathrm{M} \mathrm{KOH}$ $298 \mathrm{~K}$ and atmospheric pressure (101 kPa).

\section{RESULTS}

\subsection{Introduction}

Applying the alternating current impedance method, the ohmic resistance of the electrolytic cell is usually determined from the complex plane plot in which, at various frequencies, the real component of impedance, $Z$, is plotted $v s$ the imaginary component of impedance, $Z$ ". The intersection of the $Z^{\prime \prime} / Z^{\prime}$ curve with the $Z^{\prime}$ axis at $n \rightarrow \infty$ denotes the ohmic resistance of the cell.

To minimize the number of measurements and prevent alteration of the nature of the elect rode surface during a series of experiments, $Z^{\prime}$ and $Z^{\prime \prime}$ were mostly determined at frequencies higher than about $1 \mathrm{kH} z$, where generally $Z^{\prime \prime} \leqslant Z^{\prime}$.

Because the surface area of the working electrode is much smaller than that of the counter electrode and the distance between both electrodes is much greater than the diameter of the working electrode, the experimental $Z^{\prime}$ at $Z^{\prime \prime}=0$ and at $r \rightarrow \infty$ is practically equal to the ohmic resistance, $R$, of a solution layer at the working electrode. For a similar case, Newman[3] has deduced theoretically that $R=\rho / 2 d_{\mathrm{e}}$ where $\rho$ is the specific resistance of solution and $d_{e}$ is the diameter of the working electrode.

The $Z^{\prime \prime}-Z^{\prime}$ curves for hydrogen evolution and for oxygen evolution at $i<1.5 \mathrm{~A} \mathrm{~cm}^{-2}$, have the usual shape. At higher currents, however, a remarkable shape is obtained. The $Z^{\prime \prime}-Z^{\prime}$ curve reverses at a frequency depending on the current and nature of the gas evolved. Below this frequency the slope of the $Z^{\prime \prime}-Z^{\prime}$ curve is negative; even a negative $Z^{\prime}$ has been found. This effect may be caused by the periodic bubble phenomenon, that is formation and detachment of bubbles.

The ohmic resistance $R$, ie $Z^{\prime}$ at $Z^{\prime \prime}=0$ in the highfrequency range, was determined by interpolation of the $Z "-Z$ ' curve.

For hydrogen series, $R_{0}$ was obtained by determining $R$ at $i=0$ and various frequencies and/or by extrapolation of the $R / i$ curve. For oxygen series, $R_{0}$ was determined only by extrapolation of the $R / i$ curve, since $R_{0}$ cannot well be determined from measuring the $Z^{\prime \prime}-Z^{\prime}$ curve at $i=0$.

It has been found that $R$ increases with increasing current density owing to the presence of bubbles in the solution at the working electrode. The bubble effect upon the resistance $R$ is given by the reduced resistance increase $\Delta R^{*}=\left(R-R_{0}\right) / R_{0}$.

The determination of $R_{0}$ was the most accurale for the hydrogen series. For these series the reverse of $\boldsymbol{R}_{0}$ increases linearly with increasing diameter of the disc electrode for diameters from 1 to $4 \mathrm{~mm}$. The experimental $R_{0}$ for the hydrogen series was about $10 \%$ less than the one calculated from the relation $R_{n}=\rho_{0} / 2 d_{\mathrm{r}}$.

Generally, $\boldsymbol{R}_{0}$ for the oxygen series was about $5 \%$ higher than $R_{0}$ for the hydrogen series. This difference in $R_{0}$ may be caused by formation of an oxide layer on the electrode during oxygen evolution. As the main aim of this investigation is to determine the bubble effect 
on resistance $R$, no particular attention was paid to the observed difference in $R_{0}$.

\subsection{Effect of diameter and position of working electrode}

The effects of both factors on $\Delta R^{*}$ were investigated for a hydrogen as well as an oxygen-cvolving nickel electrode in $7 \mathrm{M} \mathrm{KOH}$ at $298 \mathrm{~K}$ and atmospheric pressure. Only the results obtained with hydrogenevolving electrodes were useful in clearly showing the influence of both factors.

$\Delta R^{*}$ is plotted as a function of current density on a logarithmic scale resulted in straight lines. Figure 2 shows results for hydrogen-evolving vertical nickel electrodes with various diameters. This figure also shows that the slope b of the $\log \wedge R^{*} / \log i$ curve does not depend on the diameter of the working electrode but that $\Delta R^{*}$ decreases with increasing diameter of the working electrode. It has been found that the diameter variation from 1 to $4 \mathrm{~mm}$ of a horizontal electrode has no clear effect on $\Delta R^{*}$ at various current densities. Moreover, the slope $b$ for a horizontal electrode was equal to that ubtained for a vertical electrode.

\subsection{Effect of electrode material and nature of gas evolved}

Figure 3 shows results for hydrogen evolution on various electrode materials in $7 \mathrm{M} \mathrm{KOH}$. The results are given by parallel straight lines. Their slope $b$ is about 0.6. The bubble effect on $\Delta R^{*}$ decreases in the sequence $\mathrm{Pt}, \mathrm{Ni}$ and Au. Owing to differences in position and surface area of the glassy carbon electrode, glassy carbon is not referred to that series. Nevertheless, its slope remains about 0.6.

Characteristic results for oxygen evolving electrodes are shown in Fig. 4. A negative slope of the $Z^{\prime \prime}-Z^{\prime}$ curve in the high-frequency range occurs at $i>1 \mathrm{~A} \mathrm{~cm}^{2}$ for $\mathrm{Pt}$ and $>1.5 \mathrm{~A} \mathrm{~cm}^{2}$ for $\mathrm{Au}$ and $\mathrm{Ni}$ electrodes. Figure 4 shows that the electrode material affects both $\Delta R^{*}$ and the shape of the $\log \Delta R * / \log i$ curve.

To support the results obtained by impedance measurements, we determined the relation between current density and ohmic potential drop between a tip of a Luggin capillary and horizontal nickel clectrode for oxygen and hydrogen-evolution, measured by the current-interruptor technique. The ohmic resistances determined by the current-interruptor technique were

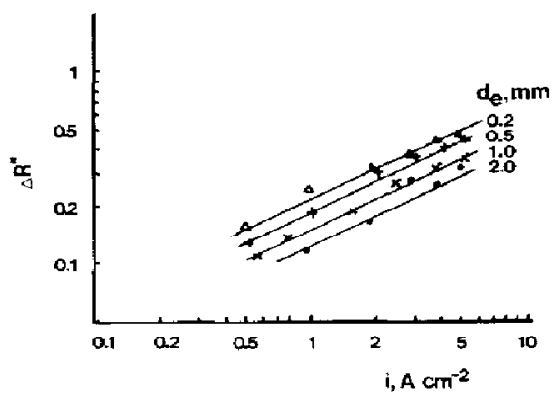

Fig. 2. $\Delta R^{*}$ is plotted vs $i$ on a logarithmic scale for hydrogen-evolving vertical nickel electrodes of various diameters.

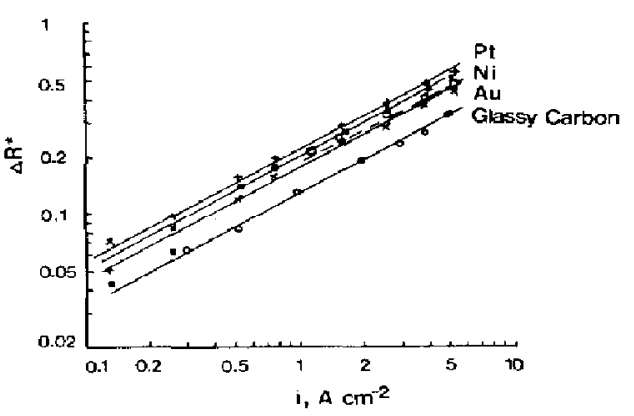

Fig. 3. $\Delta R^{*}$ is plotted $v s \cdot i$ on a logarithmic scale for hydrogen-evolving horizontal $\mathrm{Ni}, \mathrm{Pt}$ and $\mathrm{Au}$ electrodes with $1.0 \mathrm{~mm}$ diameter and for a hydrogen-evolving vertical glassy carbon electrode of $2 \mathrm{~mm}$ diameter. Moreover, $\Delta R^{*}$ determined by current-interruptor tochnique is given by a dotted line for a hydrogen-evolving horizontal Ni electrode of $1 \mathrm{~mm}$ diameter.

about $25 \%$ smaller than the one from impedance measurements. Both $R_{0}$ and $\Delta R^{*}$ were analogously obtained as described for impedance measurements. $\Delta R^{*}$ determined by interruptor measurements is plotted $v$ s current density on a logarithmic scale in Fig. 3 for a hydrogen-evolving electrode and in Fig. 4 for an oxygen-evolving electrode. These figures show that $\Delta R^{*}$ is independent of the measuring method, taking into account in particular the inaccuracy of $R_{0}$.

The effect of the presence of gas bubbles of different size in a solution on the specific resistance of that solution can be calculated with the well-known Bruggemann equation $\rho=\rho_{0}(1-\varepsilon)^{-3 / 2}[10]$. To determine the gas void fraction in a solution layer at the gas-evolving electrode, gas bubbles present on the whole surface of both the hydrogen and the oxygen-

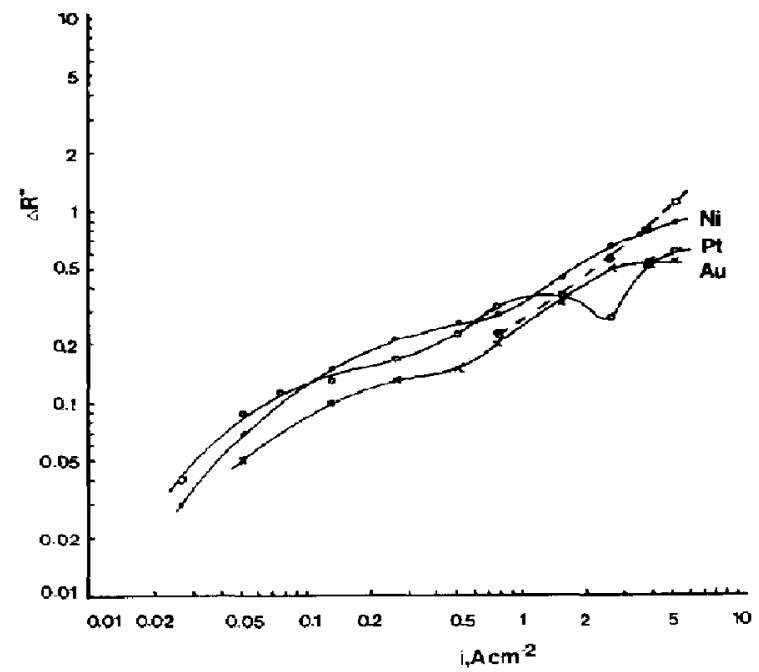

Fig. 4. $\Delta R^{*}$ is plotted vs $i$ on a logarithmic scale for oxygenevolving horizontal $\mathrm{Ni}, \mathrm{Pt}$ and Au electrodes. Moreover, $\Delta R^{*}$ determined by the current-interruptor technique is given by a dotted line for an oxygen-evolving horizontal Ni electrode. 


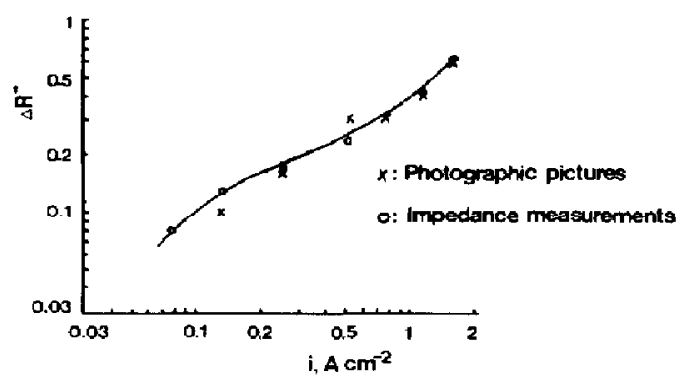

Fig. 5. $\Delta R^{*}$ is plotted us $i$ on a logarithmic scale for an oxygen-evolving horizontal nickel electrode. The results from impedance measurements are indicated by $o$ and those from photographic experiments at which the Bruggemann equation was used at the calculation, are indicated by $\times$. Both series of experiments were carried out simultaneously.

evolving horizontal nickel electrode in $7 \mathrm{M} \mathrm{KOH}$ and at $298 \mathrm{~K}$ and atmospheric pressure were photographed according to the usual method

It has been found that for the hydrogen-evolving electrode this method is not applicable since also bubbles above the electrode surface were pictured. So adhered and detached bubbles could not be distinguished. No other useful method is known.

For the oxygen evolving electrode below about $2 \mathrm{~A} \mathrm{~cm}^{-2}$ the bubbles present on the electrode surface were sharply pictured and almost no detached bubbles were photographed. Moreover, detached bubbles could easily be detected. From the number of detached bubbles on a picture and the diameter of each detached bubble Sillen[4] has calculated, assuming a zerocontact angle,

$$
\begin{aligned}
\Delta R^{*}=\left(R-R_{0}\right) / R_{0} & =\frac{1}{0.125 \pi d_{\mathrm{c}}} \\
& \times \int_{0}^{0.125 \pi d_{\mathrm{e}}}[1-\varepsilon(x)]^{-3 / 2} \mathrm{~d} x,
\end{aligned}
$$

where

$$
\varepsilon(x)=\sum_{m=1}^{m=m_{e}} \frac{4\left(D_{b} x-x^{2}\right)}{d_{e}^{2}} \text { for } x \leqslant D_{b}
$$

The value of factor $\varepsilon(x)$ is equal to the degree of screening of the electrode surface by adhered bubbles at a distance $x$ from the electrode surface.

Figure 5 shows also $\Delta R^{*}$, determined from 4 pictures for each current density, as a function of the current density on a logarithmic scale. In this figure $\Delta R^{*}$, determined by impedance measurements which were carried out simultaneously with the taking of the photographs.

\subsection{Effect of $\mathrm{KOH}$ concentration}

Figure 6 shows $\log \Delta R^{*} / \log i$ curves for hydrogenevolving electrodes in various $\mathrm{KOH}$ concentrations. All curves in Fig. 6 are linear and their slope b decreases with increasing $\mathbf{K O H}$ concentration.

Results for oxygen-evolving electrodes are given in Fig. 7. The shape of the $\log \Delta R * / \log i$ curves depends

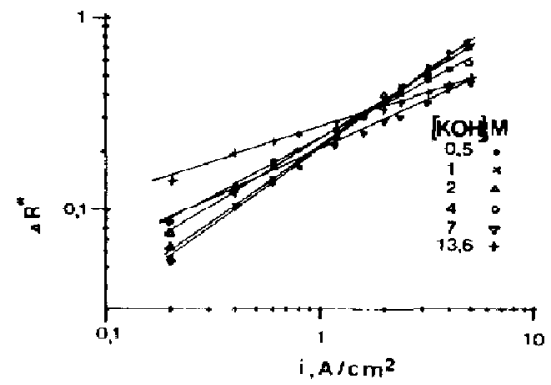

Fig. 6. $\Delta R^{*}$ is plotted vs $i$ on a logarithmic scale for a hydrogen-evolving horizontal niekel electrode in various $\mathrm{KOH}$ concentrations.

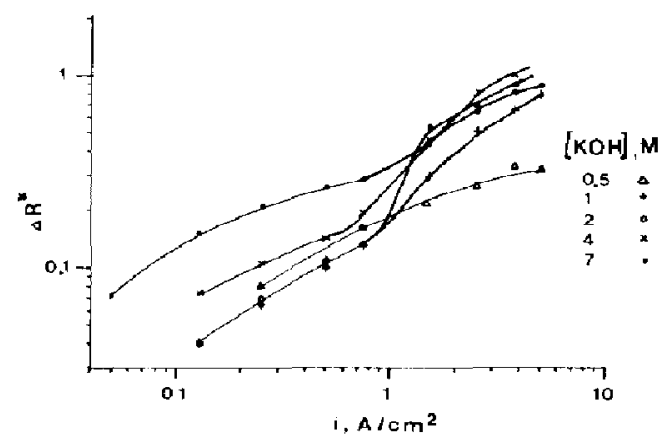

Fig. 7. $\Delta R^{*}$ is plotted vs $i$ on a logarithmic scale for an oxygen-evolving horizontal nickel electrode in various $\mathrm{KOH}$ concentrations.

strongly on the $\mathbf{K O H}$ concentration. Generally, the $\log \Delta R^{*} / \log i$ curve for oxygen-evolution in alkaline solution is an $\mathrm{S}$-shaped curve.

To check the reliability of the experimental $R_{0}$ values, the specific resistance of $\mathrm{KOH}$ solutions was determined by using a Philoscope (Philips PR 9500) and a conductivity cell with platinized platinum electrodes. The KOH dependence of both resistances agreed.

\subsection{Effect of pressure}

The pressure dependence of the $\log \Delta R^{*} / \log i$ curves was determined for a hydrogen as well as an oxygenevolving horizontal nickel electrode in $7 \mathrm{M} \mathrm{KOH}$ at $298 \mathrm{~K}$.

Results for a hydrogen-evolving electrode are given in Fig. 8 and those for an oxygen-evolving electrode in Fig. 9. All the curves in Fig. 8 are linear and parallel; their slope is 0.62 . The shape of the oxygen curves in Fig. 9 depends on pressure.

The effect of pressure on $\Delta R^{*}$ at a constant current density for gas evolution is shown in Fig. 10. The slope of the $\log \Delta R^{*} / \log p$ curve is -0.58 for the hydrogen evolving electrode.

From Section 3.3 it follows that the slope b of the $\log \Delta R^{*} / \log i$ curve for hydrogen evolution in $7 \mathrm{M}$ 


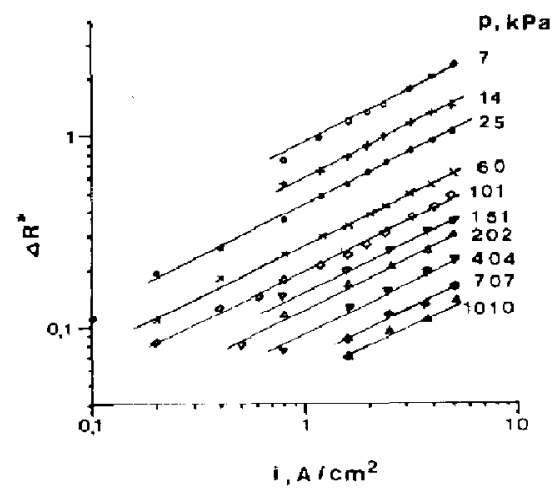

Fig. 8. $\Delta R^{*}$ is plotted us $i$ on a logarithmic scale for a hydrogen-evoluing horizontal nickel electrode at various pressures.

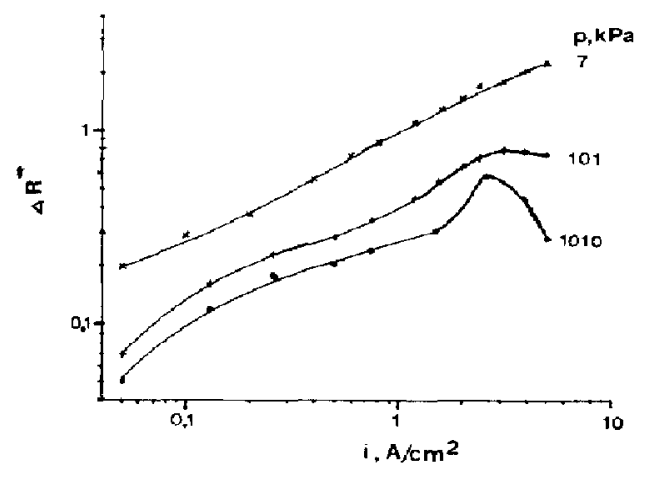

Fig. 9. $\Delta R^{*}$ is plotted vs $i$ on a logarithmic scale for an oxygen-evolving horizontal nickel electrode at various pressures.

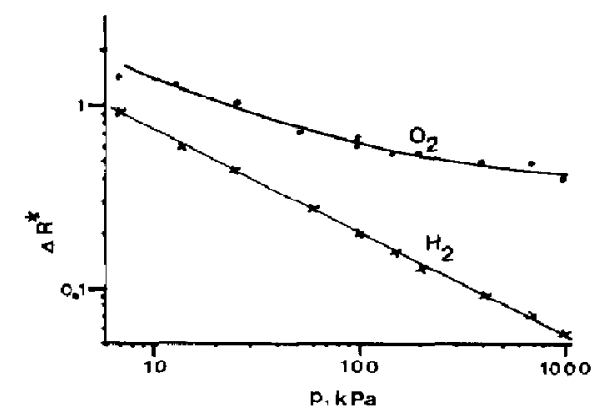

Fig. 10. $\Delta R^{*}$ is plotted os $p$ on a logarithmic scale for a hydrogen-and oxygen-evolving horizontal electrode at 1 and $2 \mathrm{Acm}^{-2}$, respectively.

$\mathrm{KOH}$ at $298 \mathrm{~K}$ is 0.60 . Taking into consideration the inaccuracy in both slopes it is concluded that, for a hydıogen-evolving electrode, $\Delta R^{*}$ depends only on the volumetric rate of gas evolution, decrease in pressure and increase in current density have the same effect on $\Delta R^{*}$.
For an oxygen-evolving electrode the slope of $\log \Delta R^{*} / \log p$ curve at $2 \mathrm{~A} \mathrm{~cm}^{-2}$ depends on pressure, for instance -0.36 at $40 \mathrm{kPa}$ and -0.12 at $404 \mathrm{kPa}$. From Fig. 7 it follows that generally the slope of the $\log \Delta R^{*} / \log i$ curve depends on current density, for instance -0.70 at $2 \mathrm{Acm}^{-2}$ and -0.31 at $0.4 \mathrm{~A} \mathrm{~cm}^{-2}$. This means that besides the effect of pressure on volumetric rate of gas evolution, the pressure has a strong influence on the coalescence behaviour of oxygen bubbles.

\subsection{Effect of temperature}

The effect of temperature on the $\log \Delta R^{*} / \log i$ relation was investigated for hydrogen as well as oxygen-evolving horizontal nickel electrodes in $7 \mathrm{M}$ $\mathrm{KOH}$ at atmospheric pressure. Results for hydrogen evolution are shown in Fig. 11 and for oxygen evoltution in Fig. 12.

The straight lines in Fig. 11 at temperatures from 298 to $343 \mathrm{~K}$ are parallel. Their slope is about 0.6 , the straight line at $358 \mathrm{~K}$, however, has a steeper slope, viz 0.78 .

The difference in slope may be explained by a strong increase in the percentage of water vapour in the gasvapour mixture. The saturation vapour pressure above $7 \mathrm{M} \mathrm{KOH}$ is $25.9 \mathrm{kPa}$ at $343 \mathrm{~K}$ and $46.5 \mathrm{kPa}$ at $358 \mathrm{~K}[5]$.

Since the gas bubbles formed on the electrode have been saturated with vapour[6] the gas-vapour volumetric ratio at $343 \mathrm{~K}$ is 2.9 and 1.17 at $358 \mathrm{~K}$. The effect

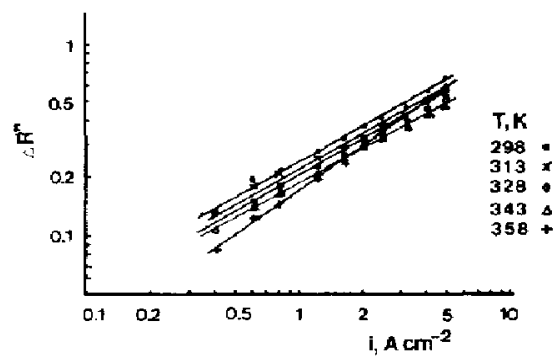

Fig. 11. $\Delta R^{*}$ is plotted us $i$ on a logarithmic scale for a hydrogen-evolving horizontal nickel electrode at various temperatures.

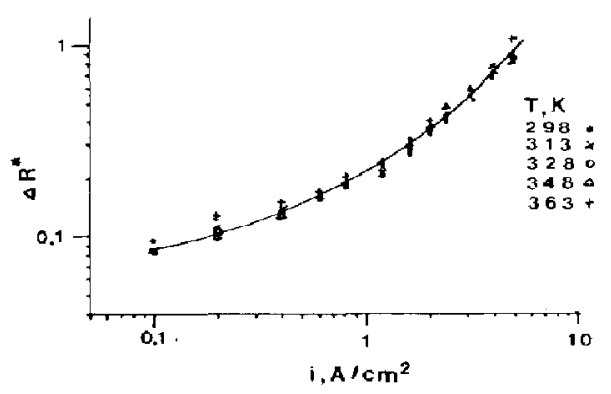

Fig. 12. $\Delta R^{*}$ is plotted vs $i$ on a logarithmic scale for an oxygen-evolving horizontal nickel electrode at various temperatures. 
of vapour on the behaviour of gas-vapour bubbles has to increase with increasing temperature.

The effect of temperature on both $\Delta R^{*}$ and the slope of $\log \Delta R^{*} / \log i$ relation for oxygen evolving electrodes is slight (Fig. 12).

\section{DISCUSSION}

This investigation is restricted to electrodes of small diameters. It is evident that the experimental data cannot be applied to large electrodes where free or forced convection play a very important role, for instance on number and size of attached bubbles.

Section 3 shows that, in particular, both the nature of the gas evolved and the $\mathrm{KOH}$ concentration affect not only $\Delta R^{*}$ but also the slope b of the $\log \Delta R^{*} / \log i$ curve.

In alkaline solution hydrogen bubbles coalesce little, whereas oxygen bubbles often coalesce[7]. Due to this difference in the coalescence behaviour of bubbles, two types of gas-evolving electrodes have been distinguished. For each type a model describing the mass transfer of indicator ions to the gas-evolving electrode is given $[8,9]$. It is likely that these two models of gasevolving electrodes are also used to explain the dependence of $\Delta R^{*}$ on the nature of the gas evolved.

\subsection{Hydrogen evolving electrode}

All $\log \Delta R^{*} / \log i$ curves are linear (Figs 3, 6, 8 and 11). The slope $b$ does not depend on the diameter, position and material of the electrode, on the pressure and temperature in the range from 298 to $343 \mathrm{~K}$, but depends significantly on $\mathrm{KOH}$ concentration. The steep slope at $358 \mathrm{~K}$ is caused by a high percentage of water vapour in the hydrogen gas-water vapour mixture as explained in 3.6 .

Slope b decreases with increasing $\mathrm{KOH}$ concentration. Since $\Delta R^{*}$ increases with increasing gas void fraction in a solution layer at a gas-evolving electrode, it is likely that the $\mathrm{KOH}$ concentration strongly affects the gas void fraction.

The solution layer at a gas-evolving electrode can be divided into two layers, viz a "fixed layer" (thickness being the diameter of adhered bubbles) adjacent to the electrode surface, followed by a "diffuse layer". To explain the dependence of $\Delta R^{*}$, it is important to determine the gas void fraction in the "fixed layer". This determination was not possible for the hydrogenevolving electrode. Generally, for a hydrugen-evolving electrode, $\log \Delta R^{*}=\mathrm{a}_{1}+\mathrm{b} \log i$ and $\log \Delta R^{*}=\mathrm{a}_{2}$ $-\mathrm{b} \log p$, where $\mathrm{a}_{1}$ and $\mathrm{a}_{2}$ are constants depending on the position, height and material of the electrode and on temperature. Pressure and current density have similar effects on $\Delta R^{*}$. The constant b strongly depends only on the $\mathrm{KOH}$ concentration.

\subsection{Oxygen evolving electrode}

Generally, the $\log \Delta R^{*} / \log i$ curve is not linear but S-shaped (Figs 4, 7,9 and 12). This result may bc caused by coalescence of oxygen bubbles depending on many factors, such as $\mathrm{KOH}$ concentration, pressure, temperature and nature of electrode material. In this case, determination of the gas void fraction in the "fixed layer" can assist explaining the experimental $\log \Delta R^{*} / \operatorname{lng} i$ relations.

For an oxygen-evolving electrode the gas void fraction was determined as a function of the distance from the electrode surface to explain the experimental $\log \Delta R^{*} / \log i$ relations. The reduced resistance increase $\Delta R^{*}$ is related to a solution layer with a thickness of $0.125 \pi d_{\mathrm{e}}$ at a gas-cvolving disc electrode with a surface area of $0.25 \pi d_{\mathrm{e}}^{2}$. For the oxygenevolving electrode almost all the bubbles within this layer are adhered to the electrode surface. So, the contribution of "free" bubbles to the gas void fraction can be neglected. Using the Bruggemann equation, $\Delta R^{*}$ was calculated as described in Section 3.3. Calculated as well as experimental $\Delta R^{*}$ are given as a function of current density in a logarithmic scale in Fig. 7. Both $\log \Delta R^{*} / \log i$ curves agree very well with each other. Consequently, the Bruggemann equation is useful to determine the ohmic resistance of a solution layer containing bubbles of different size and at which each bubble adheres to the electrode surface.

It is likely that this result is also applicable for large electrodes.

\section{REFERENCES}

1. L. J. J. Janssen, J. J. M. Geraets, E. Barendrecht and S. J. D. van Stralen, Electrochem. Acta 27, 1207 (1982).

2. R. M. de Jonge, E. Barendrecht, L. J. J. Janssen and S. J. D. van Stralen, Hydrogen Energy Progress, Procedings of the 3 rd World Hydrogen Energy Conterence, Tok yo, Japan, Vol. 1, p. $19523-26$ June (1980).

3. J, S. Newman, Electrochemical Systems, p. 344. PrenticeHall, Englewood Cliffs. N. J. (1973).

4. C. W. M.P. Sillen, private communication.

5. International Critical Tables, Vol. III, p. 373. McGrawHill, New York (1928).

6. H. F. A. Verhaart, R. M. de Jonge and S. J. D. van Stralen, Int. J. Heat Mass Transfer 23, 293 (1980).

7. L. J. J. Janssen, Electrochim. Acta 23, 81 (1978).

8. L. J. J. Janssen and E. Barendrecht, Electrochim. Acta 24, 693 (1979).

9. L. J. J. Janssen and S. J. D. van Stralen, Electrochim. Acta 26, $1011(1981)$.

10. D. A. G. Bruggemann, Ann. Phys. 24, 636 (1935). 